\title{
A contingency approach to engaging with conflicting small and medium-sized organisations
}

\section{Roger Dwan}

\begin{abstract}
This article examines conflict engagement in the workplace, particularly in smaller organisations. The attitudes to conflict of those in leadership roles can have a big impact on workplace culture and practices and the performance of the organisation. Through semi-structured interviews the viewpoints of leaders were elicited and analysed.

A contingency approach to engaging with conflict is often an effective way of dealing with conflict situations as they arise. When deciding on an appropriate course of action, effective leadership depends on matching leadership styles with the situation. Coaching is recognised as an effective way to support leaders in engaging with the conflict situation, having regard to multiple perspectives and the operating environment.

Several key themes emerged from the research and these are explored and expanded upon to develop some principles which can be used as part of a coaching model when working with leaders in smaller organisations in particular.
\end{abstract}

\section{Keywords}

Conflict, mediation, medium-sized organisations, coaching

\section{Introduction}

Workplace conflict is common in organisations of all sizes but in Small and Medium Sized Enterprises(SMEs) certain types of conflict can be particularly damaging for both individuals and for the performance of the organisation. Those people in leadership positions in these organisations have a responsibility to recognise negative conflict and engage with conflict situations in a constructive and positive way. Conflicts are often being dealt with in an informal manner close to the source.

To manage conflict effectively, it helps to be aware of our conflict engagement style and to amend this, based upon the particular conflict situation and the individuals involved. This is known as a contingent conflict style. Leaders in SMEs are confronted with conflict on a regular basis and there are times when they either need extra support from a third party or must develop their own resources so they can manage conflict effectively. Leadership conflict coaching can be helpful in creating the space for 
detached reflection, enabling the individual to choose an appropriate strategy for managing a situation. This can help leaders to improve their competence in this area, thereby improving the effectiveness of the organisation.

There may be times when the leader is not best placed to manage the conflict and an external intervention from a mediator or facilitator may be helpful. By working with a conflict engagement specialist, leaders in SMEs can help ensure that conflicts are not avoided and allowed to fester when something should be done. However, any action taken must be considered and appropriate rather than being reactive. By engaging with workplace conflicts, those in leadership positions in SMEs can create an enjoyable and productive place to work. Doing this has benefits for individuals as well as the organisation. Organisations are classed as an SME in Ireland if they employ fewer than 250 persons and have an annual turnover not exceeding $€ 50$ million, and/or an annual balance sheet total not exceeding $€ 43$ million. It is currently estimated that $68 \%$ of Irish private sector employees work for an SME and, according to the Central Statistics office, they account for $52 \%$ of total employment.

The term „conflict engagement” is used as it acknowledges that some conflicts may not be easily or permanently „resolved". However, if the parties to a conflict engage in a constructive rather than a destructive way, with positive intentions to collaboratively resolve the conflict, this may lead to better results. Also, people can learn from conflict.

Conflict engagement may include attempting to manage the conflict informally with others or seeking the assistance of an independent third party, eitherinternal or external to the organisation, to help all parties resolve the conflict in a way that is mutually beneficial. Third party interventions include mediation, facilitation and coaching for the parties to help them engage with the conflict in a positive way by seeking to satisfy the interests and needs of all stakeholders involved.

Conflict in the workplace can be very damaging and the smaller the organisation the more acutely this is felt. There is some literature available which makes the case for conflict engagement in the workplace generally and some key aspects are detailed below. There is little literature available specifically for smaller organisations. I set out to examine the following research question:

How can those in leadership positions in smaller organisations engage positively with conflict in their organisations?

\section{Literature review}

Despite the numbers of people working in smaller organisations in Ireland, there has been very little research done in the area of conflict management in smaller organisations. Some research has been done in the UK, but this was a number of years ago. Johnston (2008) developed a research paper on behalf of ACAS (The Advisory, Conciliation and Arbitration Service) on the knowledge and use of mediation in SMEs by carrying out a telephone survey of managers in 500 companies. Secondary quantitative analysis was undertaken by Latreille et al (2012). 
Many decision makers in smaller organisations are cost-conscious and need to be satisfied that there is a financial benefit from engaging positively with conflict. However, it can be difficult to measure the cost of poor practice in relation to conflict. As Budd et al explain "what" is missing is a common set of metrics for evaluating and comparing workplace dispute resolution procedures" (2008:460). It can also be difficult to determine when a conflict becomes damaging and costly.

At the very least, not addressing conflict in a positive and proactive way is a lost opportunity which can be quantified by looking at discretionary effort. According to McGuire (2014) Dana estimated that $65 \%$ of performance issues (pre as a result of conflict. By becoming a conflict-positive - that is engaging positively with conflict - an organisation with good conflict management practices can generate significant improvements in their levels of performance and productivity. Other cost factors should also be considered such as the cost of disputes, increased absenteeism, and the cost of replacing an employee who leaves the organisation because of conflict.

\section{Conflict engagement in smaller organisations}

It is helpful to examine smaller organisations as they are the place where most people in Ireland are employed and where most of us have worked. There is a particular culture in smaller organisations and, anecdotally, many believe this is derived from the style of the leader of the organisation, including their conflict engagement style. There has been little research done and very little has been written about conflict management in smaller organisations. There is no theoretical framework to study small business management and little is known about the relationship between progressive Human Resource Management (HRM) practices and performance (De Winne and Sels 2012).

Nadin and Cassell (2007), writing about the psychological contract in SMEs, conclude that there is "a more informal approach towards employment relations and the use of HRM practices" (2007:419) and this view is shared by De Winne and Sel (2012), who conclude that the "informal culture is often highly appreciated and replaces a social dialogue" (2012:194).

Those in leadership positions in smaller organisations are crucial to enabling this to happen and it is for this reason that I decided to carry out semi-structured interviews with this group in order to fill the gap in the current literature. It is hoped that by analysing their attitudes I can derive some useful insights and add to the modest body of literature and research that already exists in this area. De Winne and Sels (2012) explain that "the values, cognitive bases and capabilities of the most powerful actors in an organisation determine HRM and in SMEs the most powerful actors are owners/managers" (2012:185)

Bernard Mayer (2004) described conflict engagement as "accepting the challenges of a conflict whatever its type or stage of development may be, with courage and without automatically assuming that resolution is an appropriate goal”. (Mayer 2004:184). Kenny (2015) has written about using meta-mediation methods in Irish companies to promote conflict engagement but generally there is not much literature covering this issue.

There are certain conditions that need to be nurtured and cultivated if we are to engage properly with conflict and to make the most of the opportunity that presents itself. We need to empower people to 
deal with their own conflicts. This means allowing them to take responsibility to enter into a dialogue with the others who are part of the conflict.

\section{Leadership styles in SMEs}

It is widely accepted that there are two types of conflict, substantive and affective (Rahim 2002), also referred to as cognitive and relational conflict (Doucet 2009) or task and relationship conflict and that a moderate amount of substantive conflict can be attained and maintained in the workplace to help groups attain a higher level of performance (Rahim 2002). Affective conflict, on the other hand, impedes performance and occurs when members of the group or organisation believe that their feelings and emotions regarding some issues are incompatible. Many managers are uncomfortable with conflict and see it as something to be suppressed in all situations (Darling and Walker 2001) but a more progressive and productive view is to tolerate some substantive conflict, for instance when two or more individuals or groups disagree on the recognition of, and solution to, a task problem (Rahim 2002). It is important that appropriate strategies to engage conflict are developed and utilised by the leadership in an organisation and this is often determined by the situation.

These conflict strategies derive from various styles of behaviour which can be used when dealing with conflict. Many commentators have written extensively about conflict styles (Thomas and Kilmann 1977, Rahim et al 1992, Rahim 2002, Antonioni 1998, Moberg 1998). There is fairly widespread recognition that there are 5 main styles that we adapt when dealing with a conflict situation (De Dreuet al 2001), and that we each have a preference for a certain style. This has become known as the Dual Concern Theory and this matches concern for self or level of assertive behaviour and concern for other or level of co-operative behaviour. These styles are:

1. Accommodating (also known as obliging or yielding)

2. Competing (also known as coercive, competitive or dominating)

3. Avoiding

4. Collaborating (also called integrating or problem solving)

5. Compromising

Isenhart and Spangle (2000) cite research by Phillips and Cheston which compared the effectiveness of the five conflict resolution styles, and which found that problem solving (collaborating) was the most effective in cases involving interpersonal communication and organizational issues. All styles may have some merit and the adaption of a particular style may be preferred in certain situations. Leaders and managers in organisations must be adept at matching a particular style to the situation and this is the case particularly in smaller organisations where the styles adopted, and the strategies used, may have an impact on the culture in the organisation.

Much has been written on behavioural styles and their application relating to leadership and organisational effectiveness but "the relationship between leadership styles and conflict has been overlooked" (Doucet et al 2009:340) and writing in 2002 Rahim tells us that "existing literature on 
conflict management is deficient on strategies needed to manage conflict at the macro-level" (2002:210). Here the macro-level is the organisational rather than the inter-personal level.

There is general acceptance that it is important that leaders are aware of how to use different conflict handling styles to deal with various situations effectively.

This can also be referred to as a contingency theory of conflict management and it gets to the heart of how to manage workplace conflict effectively. Moberg (1998) describes how the contingent view holds that no one style is appropriate for all conflict types, targets, roles, or participants but instead, stylistic choice is likely to be influenced by the characteristics of the situation. Rahim (2002) cites the decision theory of leadership which describes how each leadership style is appropriate, depending on the situation, and that effective leadership depends on matching leadership styles with situations. There is little literature available examining how this applies to leaders in SMEs and how they can develop competency in this area.

The way a conflict is managed will often depend on the culture within which it exists, and this is important too when consider how it can effectively be resolved. Conflict engagement specialists need to be mindful of this. Davidheiser (2008) tells us that it is beyond argument that the role of culture in conflict resolution is an important one. As it seems likely that organisational culture comes, at least partially, from the styles and actions of the leadership in SMEs, it is important that these people understand how to engage positively with conflict. The knowledge needed in order to engage with conflict and to develop an effective contingent style for leaders in SMEs can be developed through training and other forms of leadership development but often the reality is that people do not have the time or resources to dedicate to formal education.

\section{Coaching}

Executive coaching has grown in prominence in recent years and may hold the key to cultivating the conditions where conflict engagement can succeed. Coaching uses some of the methods originally adopted in the sports field and applies this to work with executives, usually on an individual or team basis, in the workplace. In the executive coaching field, coaching relating to conflict has emerged as it has been increasingly recognised that working through conflict is an important leadership competency (Blinkert 2013). Models have been developed, including the Comprehensive Conflict Coaching Model (CCCM) (Jones and Brinkert 2008) and the CINERGY model (Noble 2011). Brubaker et al (2014) conclude that there is a move from intervention to prevention and that coaching is one of the two fastest growing areas of practice in workplace conflict management in North America. This, they argue, reflects the desire of leaders to deal more proactively with conflict in their organisations. It is likely that this trend is being replicated in Europe, including Ireland.

Noble, writing in Brubaker et al (2014), defines conflict management coaching as "a one-on-one process in which a trained coach helps individuals gain increased competence and confidence to manage and engage in their interpersonal conflicts and disputes. It is a future-focused and results-orientated 
process that concentrates on assisting clients to reach their specific conflict management objectives" (2014:360). She notes that, from communications with leadership coaches, conflict management coaching is one of the fastest growing areas of leadership coaching. Citing a survey from the Center for Leadership Development and Research 2013, she notes that much of a CEO"s role involves making difficult decisions that often have a level of conflict associated with them and that cultivating the skill of conflict management is a powerful tool to help the whole organisation. Fincher, also writing in Brubaker et al (2014), predicts "a silent revolution in the use of conflict coaching and conflict style diagnostics to resolve interpersonal and team disputes" (2014:366). It seems clear from the literature that conflict coaching is being used more often in organisations and that this can be an effective method for helping those in leadership positions to engage positively with conflict, partially through developing an awareness of their own leadership style and how this influences their actions. I will return to this subject later in the paper when analysing the research findings and developing conclusions.

\section{Research interviews}

Semi-structured interviews were conducted with 7 respondents from SMEs operating in the greater Dublin region. The interviews covered three main areas:

$>$ Types of conflict in the organisation

$>$ The impact of conflict

$>$ Barriers to and enablers of effective conflict engagement including outside interventions such as mediation and coaching.

\section{Profile of respondents}

\begin{tabular}{|c|l|}
\hline A & $\begin{array}{l}\text { Respondent A is the Managing Director of a business based in Dublin which provides storage } \\
\text { facilities for customers in the Dublin area. They employ about } 7 \text { people. }\end{array}$ \\
\hline B & $\begin{array}{l}\text { Respondent B is the Managing Director of an educational institution operating from Dublin } \\
\text { city centre which employs } 6 \text { full time staff and approximately } 30 \text { tutors, some of whom are } \\
\text { contractors. }\end{array}$ \\
\hline C & $\begin{array}{l}\text { Respondent C is one of two Directors in a medium-sized contract cleaning company based in } \\
\text { Dublin with approximately } 200 \text { employees }\end{array}$ \\
\hline D & $\begin{array}{l}\text { Respondent D is a Director of a family-owned supplier of catering materials based in Dublin } \\
\text { which currently employs } 40 \text { people with plans to add more positions in the next year. }\end{array}$ \\
\hline
\end{tabular}




\begin{tabular}{|c|l|}
\hline E & $\begin{array}{l}\text { Respondent E is a Director of a family-owned nursing home based in Co Kildare and which } \\
\text { has approximately } 140 \text { employees. }\end{array}$ \\
\hline F & $\begin{array}{l}\text { Respondent F is the Principal of an Accountancy practice which employs two } \\
\text { other accountants and advises mainly SME clients. }\end{array}$ \\
\hline G & $\begin{array}{l}\text { Respondent G is the Managing Director of an Irish subsidiary of a global logistics company } \\
\text { which employs approximately } 15 \text { employees in Ireland. }\end{array}$ \\
\hline
\end{tabular}

Several key themes emerged during the interviews and the diagram below demonstrates these in the form of a concept map. This was helpful when determining the categories and analysing the relationship between them. It is possible to draw some conclusions based upon these categories and I have attempted to build some theory based upon the findings.

The literature shows that there is a significant cost arising from conflict in the workplace and that this can be felt particularly acutely in smaller organisations due to their size and the closeness of relationships within. Performance is a key requirement in organisations in all sectors, but this is not usually measured accurately.

\section{Themes}

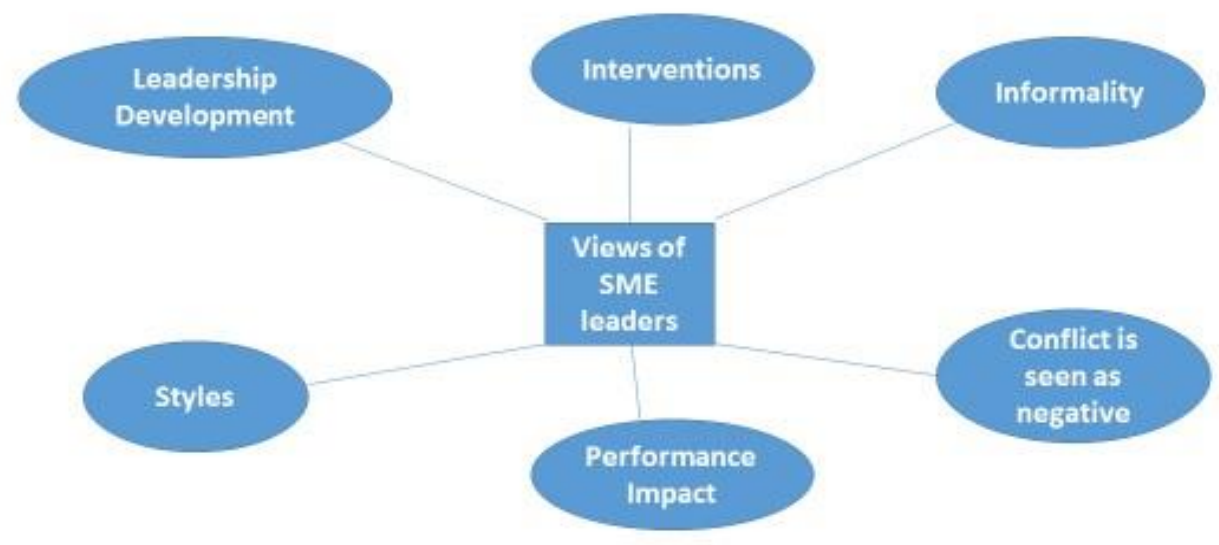

Source: Dwan 2016 
- Informality — conflict is managed informally

- Negative - conflict is spoken of in negative terms

- Performance - the impact is associated with performance issues, but this is not measured

- Conflict styles - leaders are generally unaware of the impact on organisational culture and adapt different styles depending on the situation (contingency model)

- Leadership Development - there is no formal training for those in senior positions

- Interventions - most interventions come from the leader in the first instance and they would then be open to the possibility of having an external person being involved

Performance is important for all respondents and it is somewhat surprising that performance is not measured in a more systematic and controlled way and there is perhaps an opportunity to research further this area.

There is some evidence that the use of a contingent style is more prevalent in small and medium sized organisations and that, as size and complexity increases, this becomes more important. It seems clear that there is a requirement for people to develop competence in this area, so they can better manage conflict based upon the situation (Dwan 2016).

Some organisations seem to be adept at intervening at an earlier stage in the conflict so that it does not escalate, and others appear to have a pattern of escalation, often with conflicts leading to disputes.

The informal nature of interactions in smaller organisations, as demonstrated by the findings of the research interviews, indicate that managing conflict should also be done in this informal way. The issues present themselves informally and on an ad-hoc basis for the most part, which is why timing is important for managing situations. Conflict is a negative thing that should be removed whereas the literature shows that it can also be an opportunity, particularly when it relates to task rather than relationship conflict. This seems likely to be the reason why a regular pattern is for the leadership in organisations to avoid the conflict initially in the hope that it will „blow-over". This may be a useful strategy in some cases, but it seems likely that in many cases the issues develop further until they begin to have a detrimental impact on the business, at which point the conflict has escalated into a damaging dispute, and the leadership need to react tothis.

The literature is reasonably conclusive in relation to conflict styles and demonstrates that a productive approach is to use a style depending on the situation and this is referred to as a contingent style. The findings of the research have shown that there is a lack of awareness in relation to this amongst leaders of smaller organisations and that situations are multifaceted and require examination based upon the personalities involved, the culture of the organisation, the timing of the conflict and the myriad of issues that are impacting on the situation.

To manage this effectively, leaders need to engage with the conflict and not ignore it. Depending on the characteristics of the conflict, leaders may have the capability to intervene themselves and this 
would appear to happen regularly and is in keeping with the informal nature of conflict in these organisations. As the findings from the research have shown, many people have not received formal training in this area their ability to deal with these issues will vary widely. People are often drawn to a preferred conflict style which influences their responses and pattern of behaviour.

Leaders should be self-aware enough to know their own capabilities and when they need to take a more detached view and step back and analyse the situation. Only then can they identify and use a contingent style that "fits" the particular situation. Working with a coach can be particularly beneficial here as they will help to develop a level of competence for working with conflict and can also help create the space for the leader. This enables them to look at the situation in the light of their own values and preferred style as well as considering the needs of other stakeholders and what the conflict dynamics are and how best to intervene. Thisis the essence of conflict engagement and is likely to lead to more positive and productive outcomes.

There are times when the leader's interventions in a conflict are not effective or where the leader is an involved party in the conflict and it is at times like this that an external intervention should be considered, for instance mediation or facilitation. These findings are discussed further in the final sections of the paper.

\section{Discussion}

There are relationships between the 6 categories and, using a grounded theory approach to coding and analysis, I have established the core category to be theuse of a contingent style when engaging with conflict that considers the needs of the self, others and the wider ecosystem. This is suitable for the informal nature of the workplace, can move conflict from being something negative to be avoided to a positive opportunity which improves performance levels. This contingent style can be cultivated through learning and outside intervention whenappropriate.

Leaders can then take action based upon the situation leading to better conflict engagement and more positive outcomes.

Disengaged employees have increased powers in the modern workplace, and their influence can spread widely. Employment law protects workers, and this means that it is harder for employers to take action and many are reluctant to deal with issues for fear of the consequences, particularly in smaller organisations. Employees can decide whether to exercise discretionary effort and can perform significantly below their potential. Traditional management methods are no longer as effective as these employees need to be motivated to reach their potential.

The findings from the research demonstrates that leaders in smaller organisations are aware of the risk associated with conflict and will try to deal with it informally - which most theorists agree is the right approach. As conflict is situational, it is normal that leaders will often act on instinct and deal with an issue in the moment based upon what they believe is the right thing to do. As the research demonstrates, they have often received little or no training and may not be equipped to deal with a particular issue. 
This general lack of awareness of conflict styles means that leaders will generally not take a strategic decision on how to manage a particular conflict. It is likely that they will take action based upon a natural preference or because of previous conditioning. Looking at the 5 conflict styles indicated in the literature, it seems likely that leaders will often avoid taking action initially, which in some cases may be the correct strategy but, in many cases, it may not be a viable long-term action. Leaders will know what their needs are, but they may either feel these are not achievable because of the perceived legal risks in the workplace or the threat of withdrawal of discretionary effort. The easiest option, therefore, is often to avoid dealing with the conflict. But there are times when the conflict must be addressed, and it seems likely that it is at times like this that leaders choose a competitive strategy, and this is often when conflict escalates.

There can often be a perception that people's needs and interests are incompatible but, in my view, this is usually not the case and if you explore a situation creatively you will likely find a common area. In order to move to collaboration with the needs of others, in many cases fellow employees" needs have to be explored and understood. Often a solution can be found that meets everyone's needs but this means time should be set aside to enter into a dialogue, so that a creative solution can be found. This will help build trust and commitment and should increase performance levels over time.

This approach requires a change from the traditional mindset to one that considers mutuality and interdependence in an organisational setting and it can be difficult for someone to do this if they have never had training in the area. Even for those who have the necessary expertise, we often have blind spots and need support with this. Conflict engagement specialists can help people to understand the current situation, their needs and the needs of others as well as their options. This support will create the space that allows them to make a more informed choice and to take the necessary action. It will also help leaders to learn from „real-life" situations which is often more valuable than theoretical classroomlearning.

A contingent style is intentional, and leaders should act strategically after they have inquired into the situation, the conflict points, their own needs, the needs of others and the wider ecosystem. To develop the appropriate strategy, wider perspectives should be considered and this can potentially mean a new way of thinking about a complex situation. By putting the various pieces of the puzzle together, the plan of action will be strategic and integrated and will allow the leader to build cohesion.

In the literature review, reference was made to the role of coaching in conflict situations and how this is likely to become more prominent in the future. This intervention is very suitable in smaller organisations as it combines support in developing an effective plan for action with learning based upon real situations, thereby increasing conflict competence. This is a key requirement for all those in a leadership position, but particularly for those in smaller organisations whose actions have an influence on organisational culture. The link between conflict styles, strategies and its impact on organisational culture is something which anecdotally is apparent, and which could be the subject of further research.

The themes which emerged during the research (Dwan 2016) can be expanded upon to develop principles, which can be incorporated into a model of coaching that can be used effectively with leaders in smallerorganisations. 
$」$ Informality - conflict situations are best dealt with informally and the timing of action is important, it is therefore important to map the situation and the system from within which it emerges on a regular basis.

\rfloor Conflict is seen as negative - a new perspective is required to look upon it as an opportunity for higher performance levels.

\rfloor Performance impact - by measuring performance and the improvement in performance levels that come from engaging difficult situations it is easier to demonstrate the return on investment (ROI). This is important in business, particularly in smaller organisations who can be more cost conscious.

$」$ Leadership development - there is little formal leadership development iplace and leaders need support to understand their own needs and values and they also benefit from understanding the perspectives of others.

$」$ Conflict styles - when planning for action leaders should take account of their own default style and decide how they are going to engage the conflict in a strategic way using what they know about the situation and their own needs and the needs of others, including the organisation. This is a strategic contingency approach to conflict engagement and the leader should commit to either accepting the situation or taking action

$」$ Interventions - if action is required interventions can take many forms and determining the most useful one will depend on the situation. Often the leader is best placed to take action themselves in the form of a conversation or facilitating a conversation between colleagues. Other times they may look for external support from an independent consultant, mediator or facilitator. The research findings show that leaders of smaller organisations are open to the possibility of working with a mediator to resolve conflicts (Dwan 2016)

Coaching is developmental and can also help a leader to reflect on and review a conflict situation after they have engaged with it. This can enable them to further develop themselves. By working through a conflict model, which follows the principles as described above, leaders will engage the conflict more effectively with better results.

\section{Conclusion}

It was clear from a review of the literature that there is a knowledge gap in relation to how leaders in SMEs can engage positively with conflict. This is a relatively modest piece of research due to the limitations of the paper but there is scope for further research and funding could be sought to pursue this. It is clear from the research conducted that conflict exists in these organisations and the style of the leader, as well as their experience and expertise, play a part in determining whether they engage constructively with conflict or if issues are dealt with in a more reactive way. There are times when this engagement is required from those in leadership positions, whether that be in relation to their own conflicts or conflicts amongst other employees that have the potential to impact upon the organisation. Awareness that conflict exists is an important first step and it is helpful to understand the needs of those 
involved in the conflict as well as those of the organisation. This situational awareness is instinctive for some leaders, but it can also be cultivated and developed.

This is a developmental process and having an expert work with those in an organisation in a coaching capacity can help develop this awareness and the preferred course of action. There are times when the conflict is better managed by an external consultant or mediator and it is important for leaders in organisations to understand when this is the case. Conflict engagement specialists can help a client to pick through the conflict situation and determine the best course of action at a time.

Leaders can develop competence in this area, which I believe is a core leadership attribute, and can engage positively with conflict in their organisations. This can be done initially by developing a contingent style which means they will engage with the conflict by examining the situation and deciding on the best way to become involved. 


\section{References}

Antonioni, D. (1998) "Relationship between the big five personality factors and conflict management style ${ }^{\text {ee }}$ International Joumal of Conflict Management Vol 9,Pages 336-355

Brinkert, R. (2013), "The Ways of One and Many: Exploring the Integration of Conflict Coaching and Dialogue-Facilitation", Group Facilitation, No 2, Page 45

Brubaker, D., Noble, C., Fincher, R., Park, S.K. \& Press, S. (2014), "Conflict Resolution in the Workplace: What Will the Future Bring?", Conflict Resolution Quarterly, vol. 31, no. 4, pp. 357-386

Budd, J. \& Colvin, A. (2008) „Improved Metrics for Workplace Dispute Resolution Procedures: Efficiency, Equity, and Voicee ${ }^{e}$. Industrial Relations Vol 47, No 3, July 2008 pages 460-479

Darling, J.R. \& Earl Walker, W. 2001, "Effective conflict management: use of the behavioral style model" Leadership \& Organization Development Journal, vol. 22, no. 5, Pages 230-242

Davidheiser, M (2008) „Race, Worldviews, and Conflict Mediation: Black and White Styles of Conflict Revisited"e. Peace and Change Vol 33, No 1, January 2008 Pages 60-89

De Dreu, C., Evers, A., Beersma, B., Kluwer, E.S. \&Nauta, A. (2001), "A Theory- Based Measure of Conflict Management Strategies in the Workplace", Journal of Organizational Behavior, vol. 22, no. 6, pp. 645668.

De Winne, S., and Sels, L., (2012) "Progress and prospects for HRM-Performance research in small and medium size businesses" In: Guest, D.E., Paauwe, J. and Wright, P. eds., 2012. HRM and performance: Achievements and challenges. John Wiley \& Sons.

Doucet, O., Poitras, J. \&Chênevert, D. (2009), "The impacts of leadership on workplace conflicts", International Journal of Conflict Management, vol. 20, no. 4, Pages 340-354.

Dwan, R., (2016) "Developing a contingent approach to managing workplace conflict with leaders in small and medium sized enterprises" (unpublished) A dissertation as part of the Masters in Mediation and Conflict Intervention, National University of Ireland, Maynooth

Ford, J. \& Barnes-Slater, C. (2002) Measuring Conflict: Both the Hidden Costs and the Benefits of Conflict

Management Interventions. Available from www.mediate.com [accessed 2 February 2015]

Isenhart, M.W. \& Spangle, M. (2000), Collaborative approaches to resolving conflict, SAGE Publications, Thousand Oaks,

Johnston, T (2008) „Knowledge and Use of Mediation in SMEs“ ACAS Research Paper

No $02 / 08$

Jones, T. S., \&Brinkert, R. (2008), Conflict coaching: Conflict management strategies and skills for the individual. Los Angeles: Sage

Kenny, T. (2015), "Co-creating Positive Working Environments: a meta mediation perspective". Journal of Mediation \& Applied Conflict Analysis

Kilmann. R., Thomas, K., (1977) „Developing a Forced-Choice Measure of Conflict- Handling Behavior: The "Mode" Instrument Eeducational and Psychological Measurement July 1977 vol. 37

Latreille, P., Buscha, F., \& Conte, A., (2012) „Are you experienced? SME use of and attitudes towards 
workplace mediatione. The international journal of Human Resource Management 23:3, Pages 590-606

McGuire, S. (2014) The Hidden Costof Workplace Conflict. Available from www.mediate.com [accessed 27

February 2016]

Mayer, B (2004) Beyond Neutrality: Confronting the Crisis in Conflict Resolution

San Francisco, Jossey-Bass.

Moberg, P. J. (1998) Predicting conflict strategy with personality traits: Incremental validity and the five factor. International Journal of Conflict Management Vol 9, Pages 258-285

Nadin, S. \&Cassell, C. (2007), "New Deal for Old? Exploring the Psychological Contract in a Small Firm

Environment" International Small Business Journal, vol. 25, no. 4, Pages 417-443.

Noble, C., (2011), Conflict Management Coaching: The CINERGY Model. Canada: CINERGY Coaching

Rahim, M.A., Garrett, J.E. \&Buntzman, G.F. (1992), "Ethics of Managing Interpersonal Conflict in Organizations", Journal of Business Ethics, vol. 11, no. 5/6, Pages 423-432

Rahim, M. A., (2002), "Toward a theory of managing organizational

conflict", International Joumal of Conflict Management, vol. 13, no. 3, Pages 206- 235

\section{Surveys and reports}

CSO Document [Accessed 9 December 2015]

http://www.cso.ie/en/media/csoie/releasespublications/documents/multisectora

1/2012/businessinireland2012.pdf

Roger Dwan is an independent consultant, coach, mediator and facilitator. He works with individuals, teams and organisations across a number of different sectors. His professional background is in Human Resources Management and he is a member of the Chartered Institute of Personnel and Development (MCIPD) and the Mediators Institute of Ireland. He has a BA in Economics and Politics from University College Dublin and a MA in Mediation and Conflict Intervention from NUI Maynooth. Roger is particularly interested in conflict engagement, leadership development and team effectiveness in organisations. He founded Cube HR Consulting in 2014, which specialises in providing human resources services to small and medium sized organisations and International companies operating in Ireland without a full HR function. He can be contacted at roger@cubehr.ie 